\title{
European Case Studies for Impact of Market-driven Flexibility Management in Distribution Systems
}

\author{
Carlo Corinaldesi, Lukas Lang, Andreas Fleischhacker, Johannes Radl, Daniel Schwabeneder, Georg Lettner \\ Energy Economics Group, Vienna University of Technology, Austria
}

\begin{abstract}
The amount of distributed generation and consumption is growing worldwide and consequently also the need to increase the hosting capacity of distribution systems. To achieve this, possible measures include building new lines, enhancing the grid infrastructure, and providing higher efficiency of the existing grid. Several projects propose to include the control of power generation and Demand-Side-Management, like solar photovoltaic power curtailment and managing flexible demand, as a measure to increase the hosting capacity of the grid. The use of automated demand response through Information and Communications Technologies seems to be a promising solution, which can be rapidly implemented cost-effectively in distribution systems. Automated Demand Response includes a set of activities aimed to reduce or shift electricity use to improve the grid operation. Generators and consumers may be encouraged by the right incentives to activate their flexibilities and consequently increase the hosting capacity of the electricity distribution systems. For this reason, smart grid technologies are expected to play an essential role in the development of future power systems. In this paper, we present the results of different European case studies, which investigated the impact of market-driven automated flexibility management in smart grids. The findings indicate that automated Demand Response can contribute to distribution system stability and increase the renewable energy share, but also requires high computational power and complex coordination architectures.

Index Terms-Automated Demand Response, Distributed Systems, Solar energy, Flexibility Management, Information and Communications Technologies, Renewable Energy Share, Smart grid, Hosting capacity, Energy Community, Demand-SideManagement.
\end{abstract}

\section{NOMENCLATURE}

\section{Abbreviations}

$\begin{array}{ll}\text { DRES } & \text { Distributed Renewable Energy Source } \\ \text { DSM } & \text { Demand-Side-Management } \\ \text { DSO } & \text { Distribution System Operator } \\ \text { ICT } & \text { Information and Communications Technology } \\ \text { PV } & \text { Photovoltaic }\end{array}$

\section{INTRODUCTION}

The goal of the distribution system is to supply energy with economic, social, and environmental costs as low as possible. In the past, distribution systems were characterized by centralized energy generation. Nowadays, the installation of Distributed Renewable Energy Sources (DRESs) such as

(C) 2019 IEEE. Personal use of this material is permitted. Permission from IEEE must be obtained for all other uses, in any current or future media, including reprinting/republishing this material for advertising or promotional purposes, creating new collective works, for resale or redistribution to servers or lists, or reuse of any copyrighted component of this work in other works.
Photovoltaics (PVs) and wind energy in electricity systems has made the distribution system more complex, due to the varying nature of renewable energy resources. Electricity is an instant commodity which has to be consumed or stored when it is produced. As shown in several studies, the growing share of renewables increases the volatility in the electricity system. For this reason, the integration of DRESs could worsen the operation of the distribution system. The integration of DRESs to the power grid creates further significant technical challenges [1].

Renewable energy production is non-dispatchable and intermittent with intense fluctuations. As the level of penetration of renewable production is expected to increase in the future, these strong fluctuations may lower the quality of the electricity supply [2]. Moreover, global electricity consumption is facing rapid growth, as indicated by an average annual increase of $3.4 \%$ [3]. The European Renewable Energy Council affirmed that emission reduction targets would be achieved through the electrification of transport, heating and cooling sector, resulting in an expected increase in electricity consumption of around $43 \%$ [4].

It, therefore, becomes necessary to increase the hosting capacity of distribution systems, to manage the supply and demand volatilities. To achieve this, possible measures include building new lines, enhancing the grid infrastructure, and providing higher efficiency of the existing grid. Hosting capacity is defined as the maximum distributed generation penetration for which the power system operates satisfactorily [5], maintaining the power quality standards. The ordinary long-term solution to increasing the hosting capacity of the electricity grid is to build new lines or to reinforce the grid. These approaches may be slow and not costs optimal to respond effectively to the growing share of DRESs.

The current state in the literature highlights the importance of having a look at the entire problem. In the last years, several concepts to manage the stability in the distribution system were developed. The works [6], [7] and [8] present several methods for the evaluation of the hosting capacity in order to take into account different aspects related to the reliable operation of the network. [9] performed an integrated hosting

C. Corinaldesi, L. Lang, A. Fleischhacker, J. Radl, D. Schwabeneder and G. Lettner, "European Case Studies for Impact of Market-driven Flexibility Management in Distribution Systems," 2019 IEEE International Conference on Communications, Control, and Computing Technologies for Smart Grids (SmartGridComm), Beijing, China, 2019, pp. 1-6. doi: 10.1109/SmartGridComm.2019.8909689. 
capacity simulation that takes into account the effects of both medium and low voltage solar PV installations with VoltVAr compensation. The Volt-VAr compensation was able to make the solar PV generation flexible and so to significantly increase the hosting capacity of a household. Flexibility options provided by solar PV are also analyzed in studies like [10] and [11]. They demonstrated the effectiveness also, the flexibility of power control strategies. In general, flexibility can be defined as the modification of generation or consumption patterns in reaction to external signals, to provide a service within the energy system [12]. [13] shows that flexibilities can be used to reduce the conventional grid expansion or grid reinforcement costs due to the excessive share of variable generation and consumption.

Several studies as [14] and [15] shown that managing flexibility of the demand side results in increased sustainability of the smart grid, as well as reduced overall operational costs and carbon emission levels. The utilization of demand-side flexibility is an attractive opportunity to avoid excessive investments in conventional power plants and costs for balancing power [16]. [17] analyzes the importance of automated Information and Communications Technologies (ICTs) infrastructure to support a more efficient smart grid is a clear opportunity to improve the performance of Demand-Side-Management (DSM) solutions. In fact, the use of automated Demand Response through ICTs seems to be a promising solution, which can be rapidly implemented cost-effectively. Automated Demand Response does not involve human intervention, establishing reliable control strategies to exploit resources optimally. $\mathrm{Au}-$ tomated Demand Response includes a set of activities aimed at reducing or shift electricity use. These activities can improve the grid operation, adapting the demand to external signals. With the objective having a real impact, it is necessary to coordinate the demand response of several devices of several types.

In this paper, we present the results of four European Case Studies. This paper discusses measures how to integrate a higher share of DRES into the distribution system. As an overview, Fig. 1 shows the four contributions of this work:

1) Investments by the DSO: comparison of technical improvements conducted by the DSO, i.e., battery vs. grid investments.

2) Utilization of self-optimizing prosumer: analyzing the impact of different dispatch strategies of a single prosumer to the distribution system.

3) Elaboration on ICT based pooling of flexibilities: discussion of the challenges in valorizing multiple flexibilities.

4) The role of the tariff design: impacts of energy (quantity) or power-based tariffs. How pricing models can influence the behavior of prosumers electricity use.

Consequentially, we discuss the contributions and highlight future directions of implementation and research.

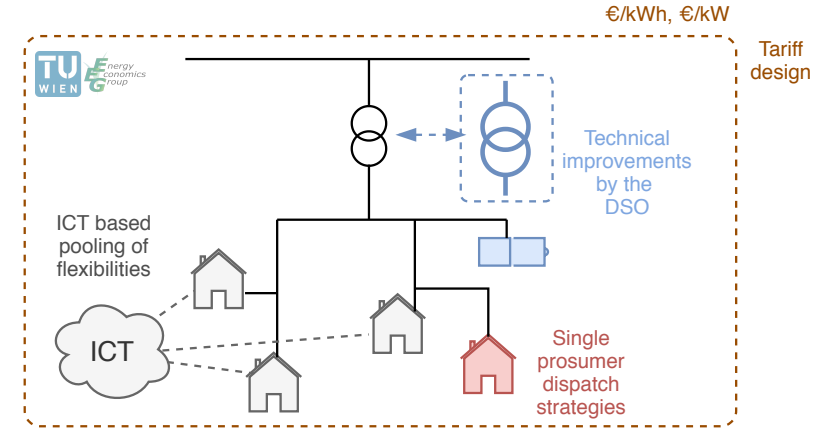

Fig. 1. Flexibility at the distribution level.

\section{CAse Studies in EuRope}

In this paper, we illustrate and examine flexibility strategies experimented and adopted by the DSOs in different European case studies to avoid investments in building new and grid reinforcement.

\section{A. Investments by the DSO}

Today, the majority of new DRES installed capacity has to be integrated into networks at distribution level [18]. To manage areas with low demand and high renewable injection and areas with energy-intensive appliances and low generation, it is necessary that DSOs increase the flexibility of the distribution system [19].

As shown in Fig. 1, flexibility can be provided by the DSO with the integration of battery systems in the grid. The flexibility of battery systems is emerging as a potentially viable technology for many distribution applications such as frequency and voltage regulation [20]. Battery systems can present potential alternatives to grid expansion or grid reinforcement.

The Austrian project BatterieSTABIL [21] investigates how grid integrated battery systems can contribute to power quality in addition to the contribution for covering the ancillary services with a high share of renewable power. Today, battery systems are used by DSOs for better grid operation and stability [22]. [21] demonstrates that future battery system operations can substitute the grid reinforcement and consequently reduce the costs in grid expansion. This can solve challenges of the grid operation, caused by decentralized and renewable power production and the resulting decomissioning of conventional centralized power plants [23].

To keep the grid voltage within the permitted limits, DSOs can introduce the $Q(U)$ control. Under this scheme, renewable generation plants feed reactive power into the grid depending on the present voltage. In contrast, under normal circumstances, renewable generating sets according to a $\cos (\varphi)$ control are currently feeding reactive power in function of their injected active power. With active voltage support, it is possible to avoid network expansion and excessive grid enhancement. Network stability can be significantly improved via the $Q(U)$ control. 
Furthermore, [24] analyzes the potential savings of grid expansion in the distribution system as part of a cost-benefit analysis. The peak shaving business model is analyzed using a battery system under a given demand evolution. The identified benefits include not only the cost savings through peak shaving, but also the saved otherwise necessary grid expansion investments. Reference grid models are used to model the costoptimal grid expansion, taking into account storage operation with and without peak shaving. The results of the simulations show that possible savings in grid expansion with battery system operation can reach $22 \%$ of the overall costs.

\section{B. Utilization of self-optimizing prosumer}

As shown in Fig. 1, the DSO can exploit the flexibility of single prosumers, offering them the right incentives. Several European projects, like [25], analyzed the impact of storages and flexibilities on grid operation and electricity costs of prosumers, testing different monetary incentives. The singleprosumer dispatch-strategy aims to minimize the costs of every single prosumer. Through ICTs, it is possible to coordinate multiple actors and to pool their flexibilities.

Leafs [25] is an Austrian project, which investigates the prosumers market-driven utilization of energy storage systems and loads flexibility. More precisely, the impact of singleprosumer dispatch operation strategies is evaluated. The strategies differ from different pricing models that the DSO applies to the prosumers. The DSO encourage the participation of the prosumers to different grid operation through suitable tariffs. The consumer can benefit from minimizing the network reinforcement costs or from achieving high self-consumption levels, depending on the tariff.

In the first simulation, shown in Fig. 2 it is assumed that the DSO applies a power tariff of $40 \mathrm{EUR} / \mathrm{kW}$ for the maximum annual feed-in power. In this scenario, the PV generation was curtailed by $10.7 \%$, to reduce the maximal feed-in power. This reduces the operational costs of the prosumer by $21 \%$.

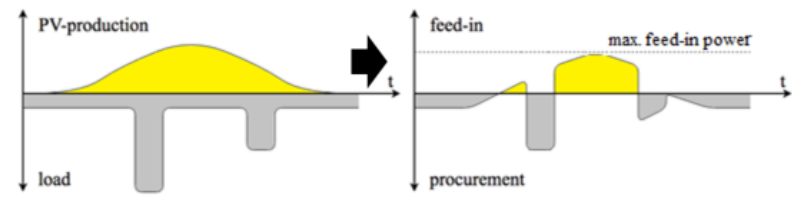

Fig. 2. Operation strategy: Minimize PV feed-in power [25].

In the second simulation, it is assumed that the DSO applies a power tariff of $40 \mathrm{EUR} / \mathrm{kW}$ for the maximum annual procurement power. In this case, the optimal operation of the flexible loads and the storage system reduces the maximum annual procurement power by $6 \%$. This reduces the operational costs of a single prosumer by $22 \%$. Additionally, alternative four scenarios were investigated, and it was demonstrated that all considered operation strategies decrease the maximum feed-in power, while the procurement power is reduced only by applying power pricing. This means that a suitable power price can be a key factor in the use of flexibility to optimize the grid operation costs. It is important to note that in these simulations, the costs for communication and controlling the power flows of the devices were not taken into account.

\section{Elaboration on ICT based pooling of flexibilites}

The DSM in case of pooling of flexibilities can be handled through ICTs, which are designed to coordinate electricity use with external signals like power system operation and energy prices. In the cases of end-users flexibilities, automated Demand Response through ICTs is necessary to exploit the external signals on shorter timescales.

The flexibility provided by ICTs is on a small-scale level. To allow small-scale technologies to contribute to the quality and efficiency of grid operation, power system regulators and operators are creating conditions for encouraging the participation of the demand-side into the wholesale energy markets lowering the minimum size of the electricity products [26]. The potential of aggregation and coordination of flexibility of small-scale devices like battery storages, electric vehicles, heat pumps, etc. in reducing the grid operational costs are analyzed in projects like [27] and [28]. These projects investigate coordination architectures to aggregate multiple flexible devices of different actors. Furthermore, the potential of aggregating flexibility of entire energy communities is investigated.

More precisely, the Austrian project Flex+ [27] investigates simple and exhaustive descriptions of flexibilities and their coordination architectures to aggregate multiple flexible actors. Flexibilities are described as virtual batteries with variable capacities and limited power inputs and outputs. In Fig. 3, for example, the virtual capacity of an electric vehicle is shown.

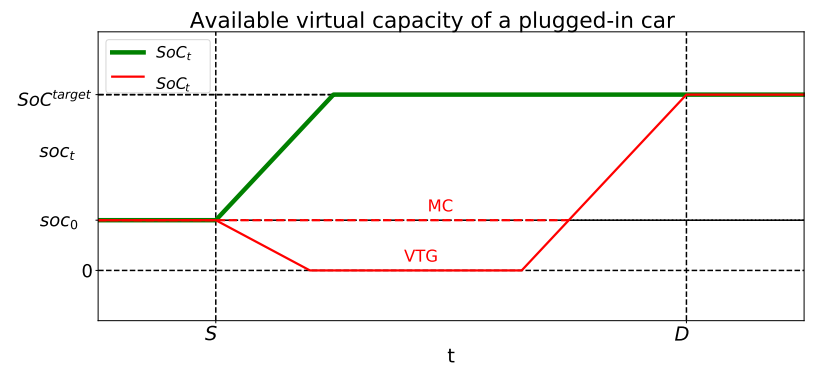

Fig. 3. Available virtual capacity of a plugged-in electric car [29].

The parameter $S$ indicates the starting time of the charging process, $D$ the ending time of the charging process, $s o c_{0}$ the initial state of charge of the batteries of the electric vehicle and $S o C^{\text {target }}$ the targeted state of charge at the time $D$. This description allows us considering a charging process of an Electric vehicle as a virtual battery with variable capacity bounds. The upper capacity bound is represented by the green line and the lower one by the red line. Flexibility may be activated within those bounds.

The project also investigates coordination architectures for multiple flexible devices. The main idea of the coordination architecture is a central Platform, which coordinates the prosumers and the suppliers and is responsible for the marketing, planning, and aggregation of prosumer flexibilities. 
Moreover, the overall flexibility of the ICTs pools is used to optimize (i) self-consumption and trading on (ii) energy spot markets and (iii) balancing markets. Therefore, a mathematical optimization problem is defined.

Furthermore, the European project PVP4Grid [28] studies the integration of residential solar PV in the power system. Aggregation concepts and business models for PV prosumers are developed to integrate sustainable and competitive electricity in the power system. Moreover, the project investigates the formation of energy communities performing activities of a DSO at a local level in eight European target countries. The purpose of energy communities is to invest in joint generation and storages for electricity and heat provision to achieve and share economic benefits. The changes in percent of the total costs (energy procurement and investments) of the energy communities in the eight European target countries are shown in Fig. 4.

The dark green bar shows the percentual costs reduction if a single prosumer invests in PV generation and storages. The light green bar indicates the saving of joint investment. The overall costs reduction is more significant for countries with more solar PV potential like Spain and Portugal. For the DSO, it is important to investigate how future energy communities can impact the grid operation. Fig. 5 shows the maximal annual feed-in and consumption power with and without forming energy communities in the eight target countries.

In Belgium, Germany, France, and the Netherlands, the maximal annual consumption power by forming energy communities increases slightly, while in the other four target countries, the maximal annual consumption power decreases. A reduction, in this case, means that in these countries, it is economical more convenient to invest in batteries and shave the consumption peaks, instead of covering the consumption peaks by the grid power. This may not be the case for the countries, where solar PV potential is not so high.

These results prove how Energy communities make PV more profitable for the prosumers and encourage their participation in the grid operation. Moreover, households with no access to PV have the opportunity to be part of a community and invest in renewable technologies. The tariff design directly drives the operational strategy of energy communities.

\section{The role of the tariff design}

With the assumption that each actor on the energy market cares only for his profit, it is glaring that suitable tariff designs can be the critical factor in the use of the flexibility of end-users. The role of the tariff design is to provide endusers with monetary incentives to enable a high degree of flexibility provision. European projects like BestRES [31], Flex+ [27] and PVP4Grid [28] investigate how aggregators and DSOs can influence the behavior of prosumers electricity use in future electricity market designs by introducing new pricing models. These projects study several market-based coordination mechanisms aimed to enable a high degree of flexibility provision of end-users.
The results show how a coordinated ICTs architecture combined with suitable pricing models can influence the DSM and ensure economic and environmental improvements to the grid actors. For example, Fig. 5 shows the maximal annual feed-in power of energy communities in eight different European countries. The DSOs in Austria, Spain, and Italy apply a maximal feed-in power tariff to their end-users. This results in a reduced annual maximal feed-in power peak. This fact proves, how a maximal feed-in power tariff can reduce the maximum annual feed-in power and reduce the need for flexibility on a distribution level.

\section{CONCLUSIONS}

This paper presents a comprehensive overview of the impact of market-driven flexibility management in distribution systems. Comparing different European Case Studies, we identify the use of automated demand response through ICTs as a promising solution for increasing economic benefits of end consumers and improve grid operations. The findings indicate that automated Demand response can contribute to distribution system stability and increase the renewable energy share, but also requires complex coordination architectures.

The DSO can provide flexibility with the integration of battery systems in the grid or by the flexibilization of single prosumers and energy communities. The DSO can be interested in lowering the electricity tariffs in return for flexibility provision. When the flexibility is provided by single prosumers or by energy communities, it is necessary to provide the endusers with monetary incentives. The results of the simulations of European projects like Leafs [25] and PVP4Grid [28] show that power tariffs could be a sufficient incentive to preserve the quality of grid operations temporarily, despite the growing share of DRESs.

Moreover, the results of the European projects prove that energy communities can incentivize the growth of the renewable share. Energy communities can make solar PV more profitable with the use of ICTs for the end consumers and encourage their joint investments.

Future research may focus on stochastic models to forecast and coordinate the flexibility of multiple energy communities to allow the DSOs to control the power quality of the distribution system efficiently. The implementation of demand, supply, and markets uncertainty in a stochastic model is necessary to define the real value of prosumers flexibilities and energy communities.

\section{REFERENCES}

[1] X. Liang, "Emerging Power Quality Challenges Due to Integration of Renewable Energy Sources," IEEE Transactions on Industry Applications, vol. 53, no. 2, pp. 855-866, Mar. 2017.

[2] C. R. a. J. Bernhardt, "Lessons Learned Along Europe's Road to Renewables," Apr. 2015. [Online]. Available: https://spectrum.ieee.org/energy/renewables/lessons-learned-alongeuropes-road-to-renewables

[3] L. Zhenya, Global Energy Interconnection. sciencedirect, 2016, vol. Global Energy Development: The Reality and Challenges. [Online]. Available: https://www.sciencedirect.com/topics/engineering/electricityconsumption 

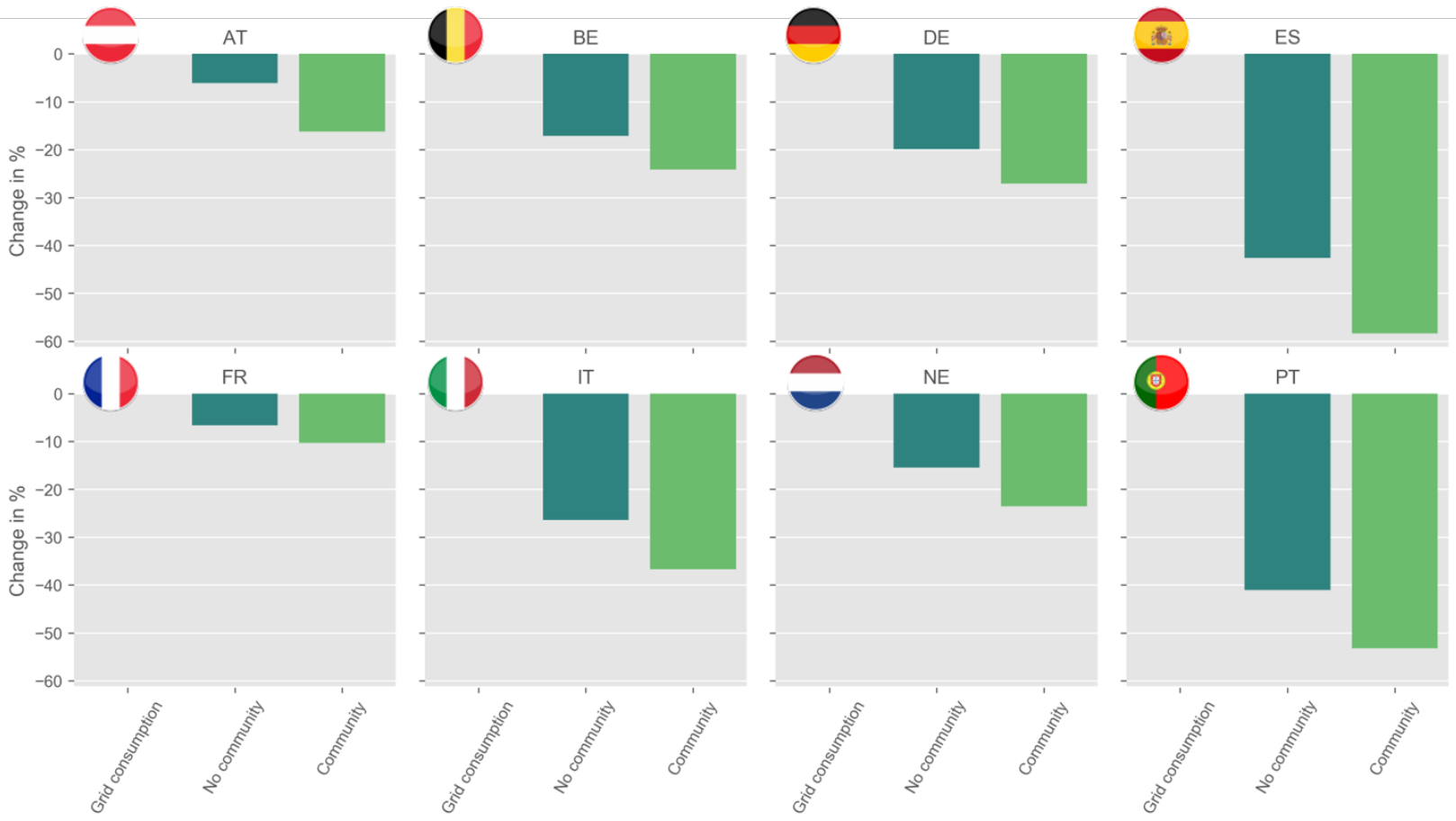

Fig. 4. Economic benefits in energy communities [30].
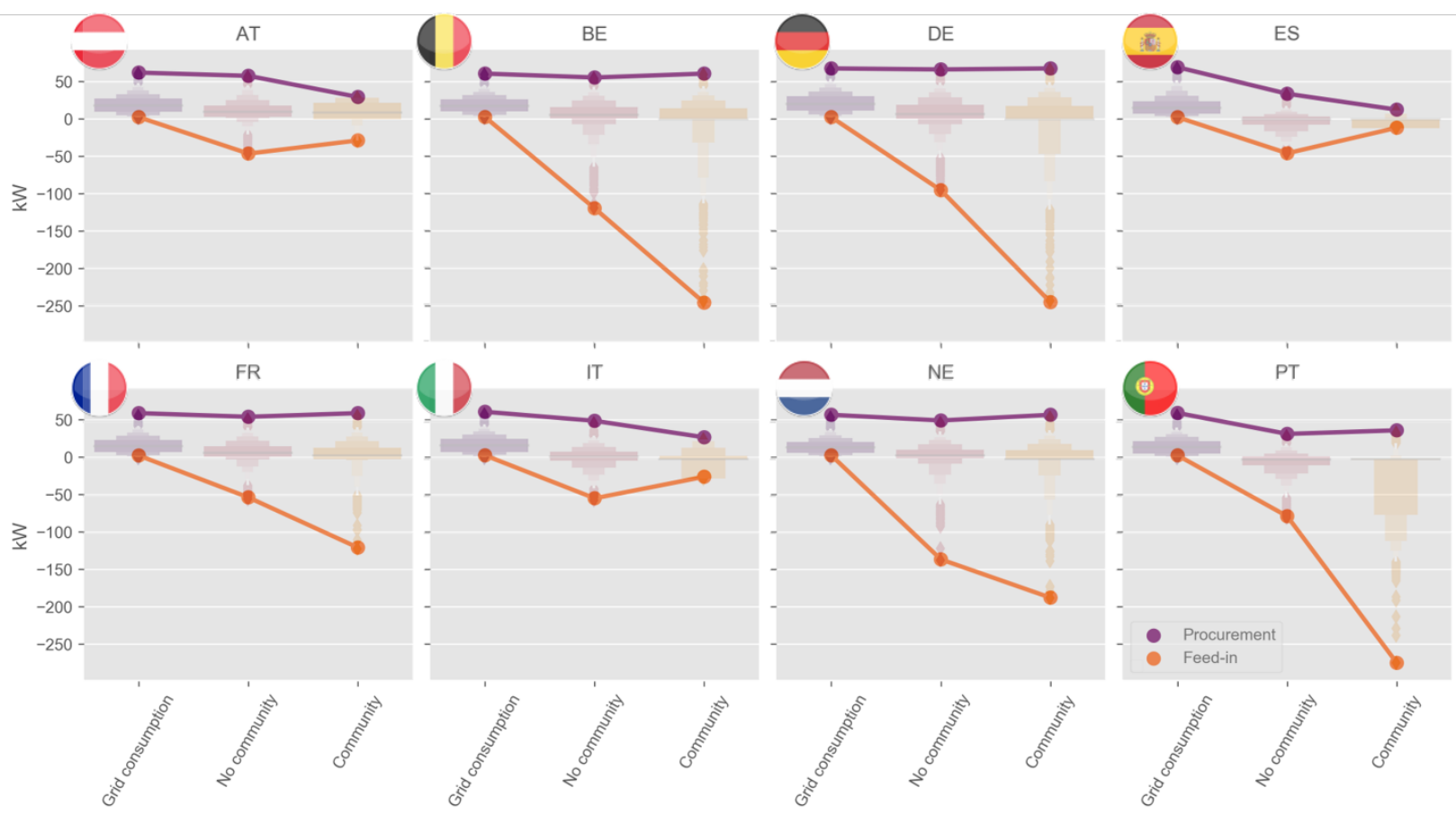

Fig. 5. Maximal annual feed-in and consumption power in energy communities [30].

[4] A. Zervos, "A $100 \%$ Renevable Energy Vision for the European Union," European Renewable Energy Council, Tech. Rep., 2010. [Online]. Available: https://warwick.ac.uk/fac/soc/pais/research/

[5] J. Varela, N. Hatziargyriou, L. J. Puglisi, M. Rossi, A. Abart, and B. Bletterie, "The IGREENGrid Project: Increasing Hosting Capacity in Distribution Grids," IEEE Power and Energy Magazine, vol. 15, no. 3, pp. 30-40, May 2017.
[6] M. Rossi, G. Viganò, and D. Moneta, "Hosting capacity of distribution networks: Evaluation of the network congestion risk due to distributed generation," in 2015 International Conference on Clean Electrical Power (ICCEP), Jun. 2015, pp. 716-722.

[7] L. K. L. Estorque and M. A. A. Pedrasa, "Utility-scale DG planning using location-specific hosting capacity analysis," in 2016 IEEE Innovative Smart Grid Technologies - Asia (ISGT-Asia), Nov. 2016, pp. 984-989. 
[8] M. Stifter, P. Zehetbauer, and B. Bletterie, "PV penetration scenario generator based on maximum hosting capacity and statistic data," in 2015 IEEE Eindhoven PowerTech, Jun. 2015, pp. 1-6.

[9] S. D. S. Anonas and J. R. C. Orillaza, "Solar PV Integrated Hosting Capacity Analysis with Volt-VAr Compensation," in 2018 IEEE Innovative Smart Grid Technologies - Asia (ISGT Asia), May 2018, pp. 1044-1049.

[10] P. Fischer, G. Alonso, M. Arenas, and F. Geerts, "Proceedings of the Workshops of the EDBT/ICDT 2015 Joint Conference (EDBT/ICDT), Brussels, Belgium, March 27th, 2015," in EDBT/ICDT Workshops, 2015.

[11] Y. Yang, F. Blaabjerg, H. Wang, and M. G. Simões, "Power control flexibilities for grid-connected multi-functional photovoltaic inverters," IET Renewable Power Generation, vol. 10, no. 4, pp. 504-513, Apr. 2016. [Online]. Available: https://digitallibrary.theiet.org/content/journals/10.1049/iet-rpg.2015.0133

[12] P. D. Lund, J. Lindgren, J. Mikkola, and J. Salpakari, "Review of energy system flexibility measures to enable high levels of variable renewable electricity," Renewable and Sustainable Energy Reviews, vol. 45, pp. 785-807, May 2015. [Online]. Available: https://linkinghub.elsevier.com/retrieve/pii/S1364032115000672

[13] M. Khederzadeh, "Defining and realizing flexibility in distribution grid," in CIRED Workshop 2016, Jun. 2016, pp. 1-4.

[14] E. K. Bish, A. Muriel, and S. Biller, "Managing Flexible Capacity in a Make-to-Order Environment," Management Science, vol. 51, no. 2, pp. 167-180, Feb. 2005. [Online]. Available: https://pubsonline.informs.org/doi/10.1287/mnsc.1040.0322

[15] T. Logenthiran, D. Srinivasan, and T. Z. Shun, "Demand Side Management in Smart Grid Using Heuristic Optimization," IEEE Transactions on Smart Grid, vol. 3, no. 3, pp. 1244-1252, Sep. 2012.

[16] S. Gottwalt, J. Gärttner, H. Schmeck, and C. Weinhardt, "Modeling and Valuation of Residential Demand Flexibility for Renewable Energy Integration," IEEE Transactions on Smart Grid, vol. 8, no. 6, pp. 25652574, Nov. 2017.

[17] F. Saffre and R. Gedge, "Demand-Side Management for the Smart Grid," in 2010 IEEE/IFIP Network Operations and Management Symposium Workshops, Apr. 2010, pp. 300-303.

[18] E. for smart grids, "Flexibility: The role of DSOsin tomorrow's electricity market," European Distribution System Operators for Smart Grids, Tech. Rep., May 2014. [Online]. Available: https://www.edsoforsmartgrids.eu/wp-content/uploads/public/EDSOviews-on-Flexibility-FINAL-May-5th-2014.pdf

[19] "A toolbox for TSOs and DSOs to make use of new system and grid services." [Online]. Available: https://www.entsoe.eu/news/2019/04/16/a-toolbox-for-tsos-anddsos-to-make-use-of-new-system-and-grid-services/

[20] L. Garcia-Garcia, E. A. Paaso, and M. Avendano-Mora, "Assessment of battery energy storage for distribution capacity upgrade deferral," in 2017 IEEE Power Energy Society Innovative Smart Grid Technologies Conference (ISGT), Apr. 2017, pp. 1-5.

[21] Austrian Institute of Technology, "BatterieSTABIL - AIT Austrian Institute Of Technology." [Online]. Available: https://www.ait.ac.at/themen/smart-grids/projects/batteriestabil/

[22] C. Vartanian, "Grid stability battery systems for renewable energy success," in 2010 IEEE Energy Conversion Congress and Exposition, Sep. 2010, pp. 132-135.

[23] C. Klabunde, N. Moskalenko, Z. Styczynski, P. Lombardi, and P. Komarnicki, "Use of energy storage systems in low voltage networks with high photovoltaic system penetration," in 2015 IEEE Eindhoven PowerTech. Eindhoven, Netherlands: IEEE, Jun. 2015, pp. 1-6. [Online]. Available: http://ieeexplore.ieee.org/document/7232489/

[24] C. Mateo, J. Reneses, A. Rodriguez-Calvo, P. Frías, and Á. Sánchez, "Cost-benefit analysis of battery storage in medium-voltage distribution networks," Transmission Distribution IET Generation, vol. 10, no. 3, pp. 815-821, 2016.

[25] Austrian Institute of Technology, "Leafs - LV Loads and Storage Integration - AIT Austrian Institute Of Technology." [Online]. Available: https://www.ait.ac.at/en/research-topics/smartgrids/projects/leafs-lv-loads-and-storage-integration/

[26] R. J. Bessa and M. A. Matos, "Optimization Models for EV Aggregator Participation in a Manual Reserve Market," IEEE Transactions on Power Systems, vol. 28, no. 3, pp. 3085-3095, Aug. 2013.

[27] Austrian Institute of Technology, "Forschungsprojekt Flex+." [Online]. Available: https://www.flexplus.at/

[28] BSW - Bundesverband Solarwirtschaft, "PVP4Grid - PVProsumers4Grid." [Online]. Available: https://www.pvp4grid.eu/
[29] C. Corinaldesi, "Flexibility of an Energy Management System," Vienna, Feb. 2019. [Online]. Available: https://iewt2019.eeg.tuwien.ac.at/programme

[30] A. Fleischhacker, "Workshop on innovation and challenges in the implementation of PV self-consumption in the EU," Brussel, May 2019. [Online]. Available: https://www.eventbrite.com/e/workshopon-innovation-and-challenges-in-the-implementation-of-pv-selfconsumption-in-the-eu-tickets-61684224175

[31] WIP - Renewable Energies, "Home." [Online]. Available: http://bestres.eu/ 